\title{
Library Instruction for the Undergraduate
}

\begin{abstract}
An effort was made to determine the current state of library instruction to undergraduates in American colleges. Literature was searched and a questionnaire was distributed to two hundred colleges. As was expected, dissatisfaction with the status quo is almost universal. A wide range of practices is reported, with the most promising future appearing to lie in the area of programmed instruction and audiovisual aids to teaching.
\end{abstract}

$I_{1}$ N REFERENCE or circulation service to college students, it is impossible to escape involvement in the frustrations of the typical college freshman. He may get lost in the maze of subject headings, cross references, or involved corporate entries at the card catalog, wandering finally into a wilderness of books, starving mentally in the midst of plenty. Reference librarians are usually only too glad to give assistance. They point out that In the Steps of the Pharaohs does indeed precede Instruction in the Use of . . . and explain the principle of word-by-word filing in the card catalog. They explain the use of encyclopedia indexes. They demonstrate the use of periodical indexes and abstracts. Yet the sobering realization comes that for the student who seeks assistance, there may well be nine others failing to use the library competently who do not ask for help.

In order to determine the current extent and effectiveness of methods of library instruction, the present author conducted a study on this topic during the summer of 1965 . The periodical literature and theses from 1950 to 1965

Miss Phipps is Associate Librarian in $\mathrm{Pa}$ cific Union College, Angwin, California. were extensively examined. A brief questionnaire was sent to two hundred colleges selected from American Universities and Colleges. These colleges were predominantly in the 500-5,000 enrollment bracket. Some attention was paid to geographic distribution: northeastern, 33; southeastern, 33; south central, 29; north central, 61; western, 42; Canadian, 2. The distribution was 119 private colleges to 81 state owned. There were 157 replies to the two hundred questionnaires, making a 78.5 per cent response.

Some 126 of the 157 respondents ( 81 per cent) indicated that some form of library instruction is given. The threepoint evaluation scale on the questionnaire (1. ineffective; 2 . of some value; 3 . of great value) was not considered a significant item in the tabulation of responses, for librarians tend to be conservative. Most of the respondents circled "of some value" in rating each type of instruction. The comments on the responses to the questionnaire were far more eloquent than the unadorned figures. Ninety-seven of the respondents added evaluations of their instruction programs. Seventy-two of these indicated that their programs were failing to meet the need. Their comments ranged from the one word "anemic" to long, articulate letters describing the glaring 
need: lack of staff, lack of time, lack of money for experimentation, lack of cooperation and interest from the faculty and administration. Excerpts taken from their comments provide the random sampling which follows.

- I think our program and most programs in institutions of rather large enrollment stinks. Programmed instruction is, I think, a possible way to accomplish something here.

- The greatest problem is to reach the students who have the greatest need and not bore those who are acquainted with what we have to offer.

- We don't give instruction because I don't believe in it. (The only completely negative response.)

- When orientation in the use of library materials on a particular subject is prepared with the cooperation of the teacher of that class, and students are aware that an assignment utilizing the materials is impending, I am convinced that there is an immediate effectiveness. Transfer of skills to other subject fields seems not to happen. The fifty minutes of initial freshman orientation assigned to the library appears totally useless except that some of the timider freshmen are herded into the library.

- We would like to report that we give adequate and effective instruction, but unfortunately our staff is too small and too busy to undertake any sort of formal instruction program.

- Our plan was to give an Orientation lecture, part slides and part lecture, to the new freshman and then early in the second semester give a very brief tour of the library with a lecture in the humanities library by one of the librarians there on the PMLA and other literary tools in research. In spite of all efforts it is still optional and first semester this year nothing was done. We think the slides and lectures are quite helpful to some of the students.

- The lack of library instruction is very obvious to those of us who man the service desks. . . . Hardly a day goes by that we don't have to send people back to the card catalog to get the complete numbers.

- I have prepared a colored slide lecture which is, basically, a tour of the library and an introduction to the card catalog, classed books, periodical indexes, and collections. The faculty is notified that this lecture is available; they arrange for their classes to see-hear the lecture if they wish. Not many so choose. We are a 24:1 faculty-student ratio, enrollment $2,800,3 \frac{1}{1 / 2}$ librarians. It's pretty much sink or swim. Faculty is excellent, but no time to help students. They either know how already and get a good education, or are lost.

Historical data for background study was best presented in concentrated form in a 1952 thesis by Mary Case Marquis. ${ }^{1}$ Two earlier theses, by Evelyn Steele Little $^{2}$ and Mabel Harris, ${ }^{3}$ also provided good material. A summary of the Marquis thesis shows that the prevalent methods of library instruction were three, and that they had not changed over the years:

1. The tour of the library during orientation week (this was considered unsatisfactory all along the line);

2. A series of lectures or lessons, varying from one to eight, sometimes as a postlude to the tour, sometimes without the tour, usually given on "borrowed time" from the English department;

3. Separate course in the curriculum, with or without credit, usually a onehour, one-semester course. ${ }^{4}$

The following reasons are given for the heretofore lack of success.

1. It has been "nobody's baby," passed to and from librarian to English teacher;

2. Librarian is chiefly an administrator;

3. Lack of time and staff;

\footnotetext{
${ }^{1}$ Mary Case Marquis, "A Study of the Teaching of Library Facilities to College Students (unpublished thesis, MS in LS, George Peabody College for Teachers, 1952).

2 Evelyn Steele Little, "Instruction in the Use of Books and Libraries" (unpublished thesis, University of Michigan, 1934).

${ }^{3}$ Mabel Harris, "Non-Professional Library Instruction in Teachers Colleges" (unpublished thesis, University of Michigan, 1934).

Marquis, op. cit., p. 45-47.
} 
4. Absence of data as to cost;

5. Difficulty of introducing a new course into the curriculum;

6. Failure of faculty and administration to recognize the need for instruction;

7. Wear and tear on reference books;

8. Tendency of students to crib;

9. Lack of student interest;

10. Poor class management;

11. Too little time for the amount of material;

\section{Too little credit given. ${ }^{5}$}

The most acceptable solution, according to the Marquis thesis, would be the onehour, one-semester course, required of all freshmen. ${ }^{6}$

The Marquis thesis, bringing the problem into focus up to the early 1950 's, is noteworthy on several accounts: first, it shows clearly that the need has been recognized principally during the twentieth century; second, modern trends of education have served to increase the use of the library and make the need more emphatic; third, the problem is still with us, although more has been written in the last decade, but there has been little enlightenment as to the best solutions; fourth, there is one significant sign of progress, that of increased use of audiovisual aids and self-teaching devices.

The respondents to the questionnaire rated the library tour the least effective, if used alone. Eighty-nine of the librarians (56.7 per cent), however, still use the library tour. Chief objection to the tour seems to be that it usually comes before the student has need to use the library, and in the midst of much other orientation, rendering the student glassy-eyed and saturated with information and admonitions. Some of the librarians used library handbooks and/or followed through with lectures in classes. Occasionally the tour was conducted

Ibid., p. 47-49.

Ibid., p. 49. in small groups, with competent guides and sufficient time to make it a demonstration-laboratory period, complete with prepared worksheets.

The orientation week lecture is not as popular today as it was twenty or thirty years ago. Only forty-six (29 per cent) of the respondents use the orientation week lecture. Only nineteen give assignments with the lecture. The same objections raised to the tour usually apply here-too early in the year, no recognized need to use the information, too academic, and too theoretical.

The orientation course, either distinctly for library orientation or with library lectures a part of a general orientation course required of all freshmen, is also used by forty-six ( 29 per cent) of the colleges. Thirty-four require the course, twelve list it as optional. For the eighteen colleges granting credit for the course, the range was wide, one to six hours of credit. Sixteen colleges allow no credit. Apparently the organization of such courses is subject to administrative interest and control.

The prevalent means of instruction is through library lectures in freshman English. Ninety-eight respondents (62 per cent) reported this form of instruction. The number of lectures ranged from one to six, with the one to three span the most frequent. Fifty-nine gave assignments with the lectures. A librarian gave the lectures in forty-five colleges; the English teacher in fifty-three. Fifty-two librarians reported lectures given in classes 'other than freshman English, listing twenty-four different areas, with education and history the most common. Comments on this form of instruction indicated that it was sporadic, usually dependent upon the invitation of the teacher.

In this day of emphasis on visual approach to learning, it is surprising that ninety-four respondents (60 per cent) used no audiovisual aids in the instruction program. Those using AV listed a 
wide variety, ranging from posters and charts to tapes, slides, filmstrips, opaque projectors, and closed circuit TV.

Only sixty-four ( 40 per cent) of the librarians used reference books for classroom demonstration. If the class is small enough (under fifty) for the students actually to see the color, size, and arrangement of the book) it is thought to be more effective to demonstrate the use of each reference book that is introduced to the class. For larger classes the instructor may find that projectors of various types, or filmstrips, will be more effective. Only three of the respondents used teaching machines with some form of programmed instruction. This method of library instruction is scarcely beyond the experimental stage, but it definitely deserves further consideration.

The increasing numbers of freshmen in colleges across the land have compounded the need for adequate library instruction. "Some institutions are already overwhelmed by trying to provide even a basic introduction to library services, and content themselves with offering each entering student a library handbook and bidding him Godspeed."7

Can this neat dismissal of the problem be its solution? Abraham Barnett comments-

The size of the library, its physical involution, the intangible complexities which must be mastered for use overwhelm and even depress them. Many do not return until an inescapable assignment, a term paper or a prepared speech forces them to do so. They come back, but without heart; and sooner or later come to the reference desk for help.

It is at this point that our attitudes are crucial. The impressions we make during this brief interview will be either a confirmation of their hopelessness or a restoration of their motivation and confidence. The one acceptable course open to the librarian is the one that makes the student

\footnotetext{
${ }^{7}$ Edward G. Holley and Robert Oram, "University Library Orientation by Television," CRL, XXIII (November 1962), 485.
}

feel he is talking with someone who has mastered the library and that he can too for his more limited purposes achieve a proportionate measure of control. 8

Daniel Gore urged that students should be taught LC subject headings, how to use the tracings on the LC card as an analysis of the book, the use of the shelflist as a bibliographic tool, and principles of bibliographic procedure. His clever analogy sums up his argument-

Certainly no responsible person would entrust a student to drive a car after such a brief period ( 1 hour) of instruction. Yet students are required to use a library, which is far more complicated than an automobile, after such a cursory introduction to its mysteries. Perhaps this happens because teachers are in no danger of being run down by libraries, but the consequences are still quite serious if one accepts the premise that self-education after college (and during it as well) is vitally important to the student. ${ }^{9}$

\section{METHODS OF INSTRUCTION}

In the analysis of the questionnaire, brief mention was made of the various methods of instruction and the frequency of use. The most common methods are now considered in more detail.

Library tour. While the tour has generally been rated ineffective as an instructional device in teaching the use of the card catalog, reference books, periodical indexes, and the like, it has been fairly effective in familiarizing students with locations of departments and services. Some colleges reported holding open house for freshmen, serving refreshments, keeping the atmosphere informal with the hope of encouraging freshmen to return for their research assignments. This is good for public rela-

\footnotetext{
${ }^{8}$ Abraham N. Barnett, "University Student and the Reference Librarian," CRL, XX (July 1959), 321.

'Daniel Gore, "Anachronistic Wizard: the College Reference Librarian," Library Journal, LXXXIX (April 15,1964 ), 1690.
} 
tions but hardly adequate for teaching the use of the library. Often student guides were used for the tours. Unless these guides are student library workers or have received intensive briefing, they can be destructive in both influence and information-a true case of the "blind leading the blind." Dorothy Hamlen, writing of her experience, includes a copy of a briefing letter sent to student guides that proved to be an excellent aid in setting the tone of the library tour. ${ }^{10}$

Another college reported that freshman English teachers brought their classes on tour of the library in small sections, giving them browsing questions to look up. ${ }^{11}$ One hopes that these tours were arranged in advance with the library staff.

At Morgan College in Baltimore (under three thousand enrollment) an interesting orientation program was conducted. The freshmen were brought in two weeks early. Two hours a day for a five-day period were allotted to the library. The freshmen were divided into small groups. They received a library workbook with assigned problems. One teacher was assigned to each group and gave informal instruction as he worked with the students. The faculty had previously received an in-service training period and did an excellent job of instruction. As a result, the teachers were more oriented to the library themselves, and the freshmen entered the school year well oriented to the library. ${ }^{12}$

The orientation lecture. The one-hour lecture on the library to large groups of freshmen is second in familiarity to the tour. Typically the services of the library are described; the policies and regula-

\footnotetext{
${ }^{10}$ Dorothy Hamlen, "Initiating the Freshman," Library Journal, LXXIX (May 1, 1954), 422-24. 11 Mary Lou Chaney, "Discovering the Library," College English, XIV (Ápril 1953), 407-408.

12 Georgetta Merrit, "Library Orientation for College Freshmen in the Small College During Orientation Week," Library Journal, LXXXI (May 15, 1956), 1224-25.
}

tions may be further delineated by mimeographed brochures; the layout of the building may be made graphic by floor plans; or elaborate, printed handbooks may be provided. In large groups, attention is easily lost and the "glazed look" may replace alert interest. Slides and films may assist in extending the attention span. Some orientation programs are lengthy enough for two library lectures. In larger universities, orientation lectures are held hourly for the first two weeks, allowing the freshmen a choice of time in which to attend two different lectures. At the University of North Carolina this plan was followed, with one added refinement: the freshmen were allowed to take a "screening test" in the use of the library. If a passing score was reached, the student was excused from the lectures. ${ }^{13}$

However good this initial lecture may be, if there is no follow-up, no testing program, no additional instruction through classes, little is likely to be retained of this early orientation instruction.

Individual instruction. No doubt the hoary definition of the perfect university -the student on one end of the log, and Mark Hopkins on the other-is familiar to all. There is much truth in it. Learning is most effective in a personto-person setting. Library instruction is no exception. The individual approach of the librarian assisting the student is the most effective, if-

1. a librarian is available for help at all times;

2. the librarian is perceptive of the student's need;

3. the student recognizes the need and asks for help;

4. the method is varied to suit the student.

\footnotetext{
${ }^{13}$ Adriana Pannevis, "Freshman Library Instruction at the University of North Carolina," North Carolina Libraries, XIII (May 1955), 113.
} 
Even at its best, individual instruction reaches only a fraction of the students. Many students do not use the library often enough to recognize their own need. Those who do are often too timid or indifferent to seek help.

There are devices and procedures used by various libraries to make individual instruction more efficient and the follow-up work more certain. Robert S. Taylor of Lehigh University described the program there in some detail, particularly a follow-up card used by the reference department. If a student's question is too complex or too time-consuming to receive immediate help, the student is asked to write his name and address on a postcard, along with the question, with the assurance that it will be searched and the assistance given by mail. Those writing on theses fill out a worksheet to be presented when requesting assistance. ${ }^{14}$

Table projectors and other self-teaching devices are used effectively in some instances, and will be considered later with audiovisual aids and programmed teaching. In spite of modern aids, however, the most important element in individual library instruction will continue to be the dedication and interest of the librarian involved.

Library instruction as a separate course. In colleges where orientation is a required and separate course, library lectures may form a significant part of the course, ranging from one lecture, with or without assignments, to four or more lectures. If library assignments are given, sections may be staggered in order that not too many will receive the instruction at the same time. This helps to avoid the traffic jams in the reference room.

What are the basic essentials that should be presented in library instruction lectures? Specific details will vary with each situation; variation will occur

14 Robert S. Taylor, "Coordinated Program of Library Instruction," CRL, XVIII (July 1957), 304-306. from year to year in the same college. No program is static. Several student library assistants who were sophomores, when asked their opinion of the prime essentials for freshmen in library usage, replied with one voice, "Teach the use of the card catalog!" One might suggest the following as minimum topics:

1. location of services in the library;

2. rules and policies of the library;

3 . use of the card catalog;

4. encyclopedias and dictionaries;

5. periodical indexes;

6. statistical yearbooks and Facts on File;

7. indexes to composites: Granger, Sutton, etc.;

8. Book Review Digest;

9. biographical dictionaries.

The first two items, along with shelving arrangement and classification system, could be presented in the library handbook, using the handbook as text material in the lectures.

When library instruction can be given in a separate required course, the needs of the students can be met without the confinement of time and space experienced when fitting units of library instruction into a general orientation course. This seemed to be the goal and preference of many of the respondents to the questionnaire. The offering of such a course requires the recognition of need from the administration and the addition of sufficient library personnel to supply the teaching staff.

A very full and practical outline for a freshman library course is given by Wilson, Lowell, and Read in The Library in College Instruction..$^{15}$ They recommend a required course, a minimum of twelve hours of instruction, and preferably twenty hours or more. Credit is usually one semester hour. There are, of course, many other excellent course outlines. The best of these can be only a guide,

${ }^{15}$ Louis R. Wilson and others, The Library in College Instruction (New York: H. W. Wilson, 1951), p. 288-89. 
for the library instructor must tailor his course to fit his situation. Gates's Guide to the Use of Books and Libraries ${ }^{16}$ is considered by some to be a fairly adequate text for such an orientation course.

Library instruction in freshman English. According to the librarians responding to the questionnaire, instruction in freshman English is the most prevalent method: 62 per cent reported instruction given by this means. Individual comments from the questionnaires on this means of instruction range from enthusiasm over the successful cooperation, to a realization of the inevitable cribbing, and finally, to a dismal lack of cooperation.

- For two years, each member of the professional staff has met with two or more sections of English 102 to give a lecture on the library as related to the freshman research paper. The staff is delighted with the plan. It has accomplished much more than the various programs given during orientation week. We seem to be recognized as individuals, rather than just "bodies behind desks."

- The basic idea of the program is very good. It integrates the library instruction with an actual English 100 term paper assignment, making the lectures more meaningful to the students in terms of their immediate needs.

- Unfortunately many English instructors do not know how to use the library themselves and apparently see no need for their students to know what they do not. Some attempts have been made combined with other orientation needs, but to no avail.

In College English, an article by Block and Mattis ${ }^{17}$ reports that after students choose their term paper topics early in the semester, the librarian comes in for two lectures, a week apart. The first lecture gives techniques of search, the second session gives help on their specific topics. Even after the scheduled ses-

\footnotetext{
${ }^{16}$ Jean Key Gates, Guide to the Use of Books and Libraries (New York: McGraw-Hill, 1962).

${ }_{17}$ Haskell M. Block and Sidney Mattis, "Research Paper, A Cooperative Approach," College English, XIII (January 1952), 212-15.
}

sions, the librarian may be invited back to give more help on different topics.

From Harding College in Searcy, Arkansas, comes a well outlined program by Annie May Alston. ${ }^{18}$

I. Time of instruction

A. Freshmen-1 week of lessons beginning in third week of the fall semester.

B. Sophomores-after freshmen instruction is completed, usually about the end of the first six weeks.

II. Courses

A. Freshmen-in Communications (Freshman English) all sections three class periods.

B. Sophomores-in World Affairs, Institutions, Humanities, Biology, Health and Safety, two class periods.

III. Objectives

A. Freshmen

1. Position of library

2. Locations of materials

3. Library policies and regulations

4. Use of card catalog, Reader's Guide, encyclopedias, dictionaries, biographical reference.

B. Sophomore level

1. Reference tools in subject area under study

2. Acquaintance with authorities

3. Knowledge of technical literature.

The problem of students cribbing on the assignment sheets is ever present. If the same uniform assignment sheet is given to all, it is easy enough for those who have done the assignment earlier to pass answers on to later sections, or for those who are enterprising to divide up the assignment, with each member of a

18 Annie May Alston, "Library Instruction on the General Education Level," Arkansas Libraries, X (July 1953), 7-9. 
group doing a few questions, and pooling the answers. In the interest of making an assignment for several hundred students easy to correct, librarians have sometimes made the cribbing too easy. There are several ways of making it more difficult to be dishonest. Nearly all of them involve more preparation and/ or more correction time.

At the University of New Hampshire, Hugh Pritchard ${ }^{19}$ reports another interesting variation to curb cheating. The students received the usual lectures on the card catalog, periodical indexes, and yearbooks. Then they were asked to find, if possible, their name in the card catalog, or one beginning with the same first three letters. They then answered a set of questions about this book (same questions used for all-the answers would, of course, vary) such as place, publisher, date, and title.

New Hampshire students also chose articles from the Reader's Guide on some subject area of their major in college and gave the bibliographic data for each article, including subject headings they selected, the abbreviations they found, and whether or not the magazine was in the library. They again looked up their family name in biographical dictionaries, and their major field in yearbooks and encyclopedias. The assignments were simple to prepare but difficult to grade; cribbing was more difficult but not impossible if a student bribed someone else to do his work for him. The wear and tear on reference books was more evenly distributed.

Verna Melum writes that at the University at DeKalb, handbooks costing fifty cents, including the Wilson pamphlet on indexes, are available. ${ }^{20}$ Worksheets emphasizing points covered in the lecture and methods of study are given out. With the worksheets are mim-

\footnotetext{
${ }^{19}$ Hugh Pritchard and others, "Library Exercise for Freshmen," Library Journal, LXXXIV (September 15, 1959), 2576-78.

${ }^{20}$ Verna Melum, "Library Instruction to 2,000 Freshmen," CRL, XXI (November 1960), 462-68.
}

eographed form sheets (uniform for all students) to be filled in with the answers to the problem. Problem cards, with clues in red, are passed out to all students. No two students in any section have the same problems. They copy the clues from the cards on their form sheets, and the problem cards are taken up by a teacher. These are used over and over, as no answers are written on the cards. Matching each problem card is a key card in green. This is given to the readers, and the correction is thus simplified. Tests are devised for machine scoring.

Eleanor Devlin feels that working with freshmen through the English classes or other small groups has a distinct advantage over the tours or large lectures:

New students will not be an amorphous mass to be herded through a perfunctory schedule that interests no one; instead they will be members of smaller classroom groups whose visits to the library will have a purpose planned by the teacher, expected by the librarian and understood by the students themselves. ${ }^{21}$

Audiovisual aids in library instruction. Audiovisual means many things to many librarians. In the responses to the questionnaire, 38 per cent reported using some type of audiovisual device. However, these were chiefly slides, filmstrips, charts, and posters. Charts and posters have been used near the card catalog or periodical indexes to depict the methods of use. These are well and good if used to supplement organized formal instruction, but they are hardly an effective substitute. Often these printed devices, even handbooks, go unread except by the more conscientious student. Slides and filmstrips are cheaper than movies or television, but again they are merely adjuncts to the lectures and may suffer from the impersonalism of mass media.

\footnotetext{
${ }^{21}$ Eleanor Devlin, "Thoughts on Freshman Orientation," Catholic Library World, XXIX (October 1957), 27 .
} 
Television, closed circuit or aired over the campus station, is good as a mass medium, perhaps preferable to the commercial filmstrips, or movies, but it is a "canned" lecture. Of course laboratory assignments would be difficult to give and impossible to follow through on when given to hundreds of students at once.

The Vu Graph projectors with transparencies, the overhead projector with transparencies, and the opaque projector are all useful aids in the classroom, usually accessory to the lecture. The overhead projector and transparencies especially work well with larger groups. Roland Moody reported the use of the $\mathrm{Vu}$ Graph and a taped narration; he was pleased that this cost only about $\$ 10$ a lecture compared with $\$ 35$ to $\$ 300$ for commercially prepared material. ${ }^{22}$

Slides have been an effective visual aid in many instructional programs. Usually the slides are locally prepared, with kodachrome shots of the library, closeups of the card catalog, indexes, or whatever is to be introduced. This can be substituted for taking the actual book to the classroom. Library policies and regulations can be presented via slides and transparencies, then reinforced by the printed handbook. Slides are a particularly useful substitute for the tour when the physical plant, locations of various rooms, loan desks, and services are shown.

An unusual adaptation of slides is described in a thesis by George L. Williams. ${ }^{23}$ This describes the use of the admatic slide projector with the slides arranged with explanatory scenarios on discs, and set up either for display use in a lobby (illustrating loan procedures) or by the card catalog (demonstrating

22 Roland H. Moody and Albert Donley, "Library Orientation for College Freshmen Using A.V. Materials for Orientation Lecture," Library Journal, LXXXI (May 15, 1956), 1230.

${ }_{23}$ George L. Williams, "An Automatic and Continuous Program of Education in the Use of Library Materials" (unpublished thesis, Kent State University, 1951 ). card catalog usage). The projector is operated by a switch and will automatically turn the disc, presenting whatever procedure is placed on the machine. The scenarios must be carefully selected and worded. The slides are held on the screen for six seconds only, and an entire sequence is run in three minutes. Captions must be brief and simple, pictures must be carefully chosen to illustrate only the details in the caption-a single idea to a caption and a picture. A sound attachment is available for the projector. A "hold" switch may be pressed to hold a picture longer than the six seconds. Table model viewers are available for individual instruction.

Slides are more flexible than filmstrips, which of course have a rigid sequence. In planning either device for a local program, extreme care must be used to get good photography, logical sequence, and only one concept to a slide. If student "actors" are used, it is wise to have the same individual in all the slides of a given sequence.

Prepared films are available which are good in library instruction. Here again, if a film can be well planned and produced on campus which illustrates the local library, it is preferable. Films are more expensive than slides or strips and more difficult to keep up to date.

Televised library instruction is used in several colleges and universities. It is either released on a campus telecast or done as a regular classroom lecture on closed circuit television. The card catalog, indexes, and reference books can be presented by this means and released to the entire Freshman English class at once, or it can be given whenever so scheduled by the teacher. If released as a regular telecast it may be run at varying times and the students may view it in their dormitories or in some classroom or auditorium. In one college, eight sessions by closed circuit television were held with four hundred in each session. There were four receivers in 
each room. The location of the libraries, special services, and card catalog were emphasized. ${ }^{24}$

The most extensive project reported in library instruction by TV has been at Illinois State University at Normal, Illinois, under the direction of Robert Hertel. A trial run was carried through with a small group of two hundred freshmen, divided into four sections: first group, all three lectures on TV; second group, two TV lectures, one live; third group, two TV lectures, one live in a large group; fourth group, all three lectures live. All received a pre-test and a post-test. There was no appreciable difference in scores. Lesson one was on the card cata$\log$ with an assignment. Lesson two included reference books (shown and described on TV). Lesson three included a test over reference and an introduction to periodical indexes with an assignment. ${ }^{25}$

Dorothy Fegerburg, in the same article, emphasized the teacher's viewpoint. There must be careful, meticulous planning of the lesson. The lecture cannot vary from the plans and the cues for the cameramen and technicians. The teacher must stay in camera range and present a pleasing appearance. The instructions for technicians and lesson plan had to be written out in full. While there is no opportunity for students to ask questions, and the personal contact is missing, this medium does make mass instruction possible early in the year. This type of teaching before TV cameras is exacting, challenging, and "the hardest work she had ever done."26

The students were asked for evaluation. Fifteen per cent were negative, complaining that they were unable to

\footnotetext{
${ }^{24} \mathrm{R}$. W. McComb, "Closed Circuit Television in a Library Orientation Program," CRL, XIX (September $1958), 387$.

${ }^{25}$ Robert Hertel and others, "TV Library Instruction," Library Journal, LXXXVI (January 1, 1961), 42-46.

${ }^{20}$ Ibid., p. 45.
}

ask questions. Sixty-six per cent thought the lectures were more interesting on TV.

Admittedly there are difficulties in the TV instruction; most, however, are surmountable. The instructor should resolve the following questions.

1. What information and data do I wish to communicate: locations, card catalog, reference works, term paper form?

2. What courses must it fit?

3. What techniques are most effective -slides, movies, mockups, narrator?

4. Is the closed circuit most effective?

Sufficient time must be allowed for planning and production; a year ahead may be needed. A TV director should examine and give counsel on the script.

Programed instruction and teaching machines in library instruction. For the novice wishing orientation to the vocabulary of teaching machines, Philip Lewis has an informative article in the Wilson Library Bulletin which describes their possible use in library instruction and gives a brief glossary of terms. ${ }^{27}$

Southern Illinois University has drawn wide interest in the field of education, and particularly in library instruction, for its pioneer experiments with teaching machines. The venture has been reported in several professional journals; in fact, practically all articles discussing teaching machines for the library refer to this project.

The experiment with teaching machines at Southern Illinois University started in $1960 .{ }^{28} \mathrm{~A}$ learning room was set aside where the teaching machine was installed. A sequence of instruction was carefully planned, with instruction

\footnotetext{
27 Philip Lewis, "Teaching Machines and the Library," Wilson Library Bulletin, XXXVI (February 1962), 464-67.

${ }^{28}$ Ralph McCoy, "Automation in Freshman Library Instruction," Wilson Library Bulletin, XXXVI (February 1962 ), 468-70.
} 
frames, picture or illustration frames, testing frames, all of which were projected in prescribed order on the screen of the machine. The student using the machine (only one at a time) operated the switch that changed the frame, so that he could regulate the speed at which he proceeded.

The University divided the freshmen participating (twelve sections of Freshman English out of 100) into three groups: four sections used teaching machines; four sections learned the same content from lectures; and four sections received no instruction at all. Pre-testing was done during the first week of school for all twelve sections. Assignment sheets were used for actual experience in the library. A post-test was administered after the instruction program was finished. The results showed no significant difference between those receiving instruction by teaching machine and those receiving it in the traditional lecture method. The control group (zero group) fell considerably below the other two, not catching up until near the end of the sophomore year. ${ }^{29}$

Five units were programed for the experiment:

1. Introduction to the library;

2. Card catalog;

3. Classification;

4. Periodical indexes;

5. Reference books.

One unit was available for a week, thus running the entire program through in five weeks.

There are two ways of programming the machine in relation to sequence: (1) the linear program, (2) the branching program. In the linear program every student had to take each step or frame in sequence just as a film strip would always be shown in the same or-

20 Paul Wendt and Grovenor Rust, "Pictorial and Performance Frames in Branching Programmed Instruction," Journal of Educational Research, LV (June 1962 ), 430-32. der-no skipping of material. In the branching program the route of sequence could vary according to errors made. If the wrong response were given to a testing frame following the instruction frame, the student was routed back for more instruction (a remedial route). Answers were given by pressing a choice of buttons. If the correct response were made, the student could choose to skip certain steps and go on to more difficult material. About one hundred and forty frames were used in each unit. The average time needed was twenty minutes. Slow students might need thirty to forty; quick students took ten minutes. In this type of instruction the student knew immediately whether he was correct or not; he was not allowed to proceed until correct answers were given. In Southern Illinois University there was the added feature of performance frames. After viewing an instruction frame, perhaps illustrating some filing principle in the card catalog, the student would be required to look up a certain heading in a sample drawer of cards by the teaching machine before proceeding to more instruction. A group of indexes and reference books were available near the teaching machine for other performance frames. ${ }^{30}$ Detailed description of the machines, with more information on linear and branching programs and performance frames is given in the McCoy article. ${ }^{31}$

The advantages of the teaching machine are many.

1. every sentence of instruction is pretested;

2. the student may work independently;

3. no teacher or library staff member is needed as an instructor;

4. the student must master a point before being allowed to proceed; there is reinforcement of learning;

${ }^{30}$ Ibid., p. 430.

${ }^{31} \mathrm{McCoy}$, op. cit., p. 470. 
5. the student must respond physically and is thus kept more alert;

6. bright students may proceed at their own speed taking by-pass options;

7. slow students may proceed at their own speed with less frustration than in a class;

8. the student knows immediately whether he has answered correctly or not;

9. the entire content must be examined and re-evaluated for worth, learning sequence, etc., before it is programed.

There are obvious difficulties, however, including the following:

1. Skill is required in programming a sequence and phrasing of questions (technicians, psychologists, and subject specialists needed);

2. Concepts are more difficult to program than information (a catalog card is easy, classification is hard );

3. Movies and sound are needed with the machine;

4. Only one student can use it at a time. A battery of machines would be needed in large universities to handle several thousand freshmen. Even four or five machines would be needed in smaller colleges. The expense would be prohibitive for most institutions. ${ }^{32}$

How then can teaching machines fit into the average library instruction program? If one is fortunate enough to have several machines available on the campus, perhaps their use could be preempted for library instruction at different times of the year. Certainly they could be most efficient for review and remedial work.

Out of the experimentation at Southern Illinois University has come the possibility of programed instruction via book form. Several texts, notably in mathematics, have been devised for individual instruction and have proved

${ }^{32}$ Ibid., p. 472. successful. Library instruction material is available from the Southern Illinois University Press in book form, programed for individual instruction. The results on the testing program are the same for book form or machine. The books are cheaper than machines, and of course each student can have access to a text. The book form is easier to use but it is also easier to cheat on mastery of information. There is no writing of answers in the text, so they can be used with succeeding classes. ${ }^{33}$

Tests. Currently, the test used most widely is Feagley, "A Library Orientation Test for College Freshmen." 34 It is devised for diagnostic, or pre-testing. Norms are available for uninstructed students. The test is not timed. Fifty to sixty minutes is the suggested time. It seems adequate as a guide to what and how much instruction is needed. Some of the questionnaire respondents suggested instructing only those students who fell below a predetermined passing mark on this test. For local comparison the test might be used again, unannounced, after the instruction program. No norms are provided for this use of the test. Other tests available are listed in Tests in Print and Buros' Mental Measurements Yearbook.

\section{Conclusions}

\section{Present conditions-}

1. Library instruction in some form is more common than it was twenty years ago.

2. Librarians on the whole agree that instruction in library usage is most acutely needed.

3. Nearly all reports of surveys indicate universal dissatisfaction that not enough is being done.

${ }^{33}$ Paul R. Wendt, "Programmed Instruction for Library Orientation, Illinois Libraries, XLV (February 1963), 74-75.

${ }^{34}$ Ethel M. Feagley and others, "A Library Orientation Test for College Freshmen," (New York: Columbia University Teachers College Bureau of Publications, $1955,12 \mathrm{p}$. 
4. There is a consciousness of overwhelming numbers of freshmen to be instructed, and of wholly inadequate staffs to meet the need.

5. There is much evidence of a lack of cooperation between college administrations and librarians and between librarians and faculty (chiefly English departments) in the question of library instruction.

\section{Methods-}

1. Library tours alone have proved to be of little value in freshmen orientation.

2. Orientation lectures usually have little value unless followed by later instruction. They usually come too early in the year for freshmen to be motivated by need.

3. Library instruction should come, if possible, during the first two months of the school year, unless scheduling of the freshman term paper takes place at varying times during the year.

4. Librarians are usually more effective instructors in library usage than instructors in other disciplines, unless the faculty member is himself well oriented to library usage and the needs of the freshman.

5. The lectures assigned to the library during an orientation credit course may be more beneficial than during orientation week, but they often lack the motivation of assignments.

6. The separate, required credit course, usually one hour for one semester, may not be possible in large universities, may not be obtainable in small colleges, but where practicable it is usually the most satisfactory coverage of library instruction for lower classmen.

7. The released-time program in freshman English (in which the librarian gives the instruction in the classroom) seems to be the most prevalent in the small-to-medium sized college. This is usually satisfactory, if the relationship with the English department is a mutually cooperative one. This too, is true of released time in other classes and departments.

8. Assignments using the books introduced are, in the experience of some, most essential to the retention of the instruction given. The students need to see the books introduced, and then use them individually in their own assignments.

9. Assignments create problems of cribbing, of heavy traffic in the reference area, of heavy use of certain books. This can be partially solved, where feasible, by individual assignments or by intelligent introduction of individual research topics by the English teacher.

10. Televised lectures are excellent as a mass medium where instruction must be given quickly to a large group, but the weaknesses are a lack of personal contact and the lack of opportunity for questions.

11. Movies, especially those locally produced, like televised lectures, are excellent as a mass medium, saving staff time and personnel. Like TV lectures, they also fail in providing adequate assignments and follow-up with personal contacts. This is a prevalent problem in many large institutions where instruction must make use of mass media, or none at all.

12. Teaching machines are excellent where numbers of students and budgets permit. When only one student can receive instruction at a time from a machine, this limits the usefulness.

13. Programed instruction in books may be the answer for large institutions where small group instruction is impossible. This is a newer medium, not thoroughly tested for library instruction, but it has possibilities.

14. Individual aid by the library staff to the struggling student is still the epitome of good instruction. True, it cannot take the place of group instruction in most colleges, for they cannot reach with personal attention all who need help. But machines, movies, or TV will never replace the helping hand of an interested librarian. 